\title{
On Perceiving Tropes
}

\author{
Przemyslaw Spryszak \\ Jagiellonian University, Krakow, Poland \\ e-mail:p.spryszak@iphils.uj.edu.pl
}

\begin{abstract}
:
In this short paper I consider Professor Bence Nanay's suggestion that representationalism can be supported by the theory of tropes. I argue that from a philosophical point of view such a support is nevertheless not very strong.
\end{abstract}

Keywords: Tropes, Representationalism, Perception.

Any scholar interested in the philosophy of perception will enjoy reading Professor Bence Nanay's fairly recent article on a supportive link between the theory of tropes and representationalism [3]. As far as I am concerned, I like the idea of such a connection very much and find Nanay's constructive approach valuable. I must admit, however, that I am not convinced that the alleged link is in fact as supportive as it is thought to be. I hope, therefore, that the reader will allow me to briefly comment on this issue and will not find my observations completely off the mark.

On page 10, under the heading "The Particularity of Perception", the author says:

Contrast the following two scenarios. In the first one, I am looking at a pillow, $\mathrm{x}$, and unbeknownst to me, it gets replaced with another, indistinguishable pillow, y. I do not notice that the two pillows are different: I have no idea that the first pillow, $\mathrm{x}$, was replaced by the second pillow, $\mathrm{y}$. In the second scenario, I am looking at a pillow $\mathrm{x}$ all along - it does not get replaced with a different pillow. The relationalist points out that the representationalist needs to have a story about how to distinguish between these two experiences.

In what follows Professor Nanay argues that if we suppose that our experiences represent, inter alia, abstract particulars (tropes), the problem for representationalism regarding the answer to that question will virtually cease to exist. Although I will present his point of view below, let me first slightly alter the initial thought experiment, that is, place a similar one under the above heading. For the sake of clarity, I will present my idea step by step.

1. Suppose that I perceive a property $P$ of an object $X$ and that this property is a trope, and that object $\mathrm{X}$ itself is also a particular. Let me assume in addition, that object $\mathrm{X}$ is unknown to me and that my experience is not enriched by previous experiences, thoughts, etc., and that the only property of $\mathrm{X}$ my sense-experience represents is $\mathrm{P}$.

2. I think that is fair to say that in such a case my experience tells me merely that "something is $\mathrm{P}$ ". 
3. Let us suppose subsequently, that object $\mathrm{X}$ was replaced by a particular object $\mathrm{Y}$ by destroying and immediately duplicating every part of $\mathrm{X}$, with the exception of that part of $\mathrm{X}$ which is causally responsible for that object having the property $\mathrm{P}$. One can also assume that I have no knowledge about that change and that the new object $\mathrm{Y}$ is similar to object $\mathrm{X}$ in every respect relevant to my previous perception of $\mathrm{X}$, and that my attitude to perception is as before, that is, as in 1.

4. I think it is fair to say that the object $\mathrm{Y}$ has the property $\mathrm{P}$ (even if we agreed that property $\mathrm{P}$ is a trope), and that when I later perceive object $\mathrm{Y}$, my experience tells me merely that "something is $\mathrm{P}$ ".

5. Now the question arises: when I perceive object $Y$ at present, does my experience tell me wrongly that $\mathrm{X}$ is $\mathrm{P}$ or rightly that $\mathrm{X}$ is $\mathrm{P}$ ? I do not think the question can be justifiably answered either way, even if we maintain that $\mathrm{X}, \mathrm{Y}$ and $\mathrm{P}$ are all particulars and that my sense-experience can represent them. My perception is in a way undecided, it does not have one definite object, the object, much less a particular one.

Naturally, I am well aware that Professor Nanay might respond immediately by citing the rest of part 4.1 of his initial response regarding the peculiarity of perception and repeating that what is at issue here is that

If we accept that the properties we perceptually represent are tropes, then we have an easy answer to this question. I attribute the very same tropes to the pillow in the two perceptual experiences. Importantly, I attribute the trope of being the very same particular token object as the one I saw a moment ago (as object permanence is supposed to be perceptually represented, see Spelke 1990, 1994), (p. 10),

and that I have missed that important factor, which obviously allows us to conclude that the peculiar experience mentioned in 4 . would simply tell me (wrongly) that $\mathrm{X}$ is $\mathrm{P}$, particularly if there were no time gap between the two experiences, as in the case that Professor Nanay considers. Alas, I would respond that even if it is an empirical fact that there is a sort of object permanence representation of a token object, as Professor Elisabeth Spelke argues, that fact seems to be of little philosophical significance $[4,5]$. What is still missing, in my opinion, is a proof that such a representation is necessarily contained in every experiential representation of any particular. Unless we are provided with such a proof, we are entitled to say only (at best) that representationalism is somewhat strengthened by a theory of tropes in the case where the standard conditions of our sense-perception obtain.

If the reader does not find my remarks very compelling, I ask him to consider the following example, which is a short story about a possible world. Suppose that I am overwhelmingly (and rightly) convinced that I live in an unstable or dynamic world where there is probability of 0.5 that the particular object I perceive was already perceived by me a moment ago, and of 0.5 that it is numerically different, that is, that it was not perceived by me a moment ago and was not replaced by the object perceived. Let us assume that in this world I always perceive objects as similar to each other, like the pillows in the above example. As a result, when I perceive an object X, my experience tells me that that the object is $\mathrm{F}$ (where the property $\mathrm{F}$ is a trope); one can arguably suppose that the trope of "being possible to be the same object as the one perceived before" is also represented. If the trope of "being possible to be the same object as the object perceived before" is preserved in the unusual (though possible) way outlined in 3-4, then there is no way of distinguishing between my experience of one persisting object and of two similar (and successive) objects. Accordingly, even if we say that objects (properties included) are indeed particulars and accept the general idea of representationalism, nevertheless as philosophers and perhaps on a less empirical level, we still face the problem of the peculiarity of perception. 


\section{References}

1. Campbell, K., Abstract Particulars (Philosophical Theory), Basil Blackwell, Oxford 1990.

2. Nanay, B. Between Perception and Action. Oxford University Press, Oxford 2013.

3. Nanay, B., Perceiving tropes. Erkenntnis, vol. 77, no. 1, 2012, p. 1-14.

4. Spelke, E., Principles of object perception, Cognitive Science, vol. 14, 1990, pp. 29-56,

5. Spelke, E., Initial knowledge: Six suggestions, Cognition, vol. 50, 1994, pp. 431-445. 